TRANS · núm. 25.2021

MISCELÁNEA $\cdot 475-490$

CIENTIFICA

\begin{abstract}
En el marco de la traducción al castellano (o al gallego, etc.) de textos destinados a la enseñanza y divulgación de la ciencia, es frecuente que el traductor deba acuñar y utilizar en su texto de llegada neologismos, sobre todo cuando tales textos reflejan la vanguardia de la investigación, hoy en día documentada casi exclusivamente en inglés. La adecuada acuñación de esos neologismos es una operación delicada que reviste importancia cultural. Los neologismos acuñables y utilizables por un traductor de textos científicos didácticos y divulgativos pueden ser de tres categorías, a saber, neologismos de significado, neologismos de forma y préstamos. El presente trabajo pasa revista a cada una de esas estrategias neológicas y, recurriendo al análisis de diversas traducciones (al castellano, al gallego y al portugués), tanto publicadas como inéditas, de artículos enciclopédicos, libros de texto y artículos y libros divulgativos del ámbito científico redactados en inglés o alemán, pondera en cada caso cuáles son las mejores opciones para el traductor.
\end{abstract}

PALABRAS CLAVE: enseñanza y divulgación de la ciencia, equivalencia traductiva, neologismo, traducción científico-técnica.

\title{
Neologismos acuñados por el traductor en la traducción de textos destinados a la enseñanza y divulgación de la ciencia
}

\author{
CARLos GARRIDO \\ Universidad de Vigo
}

\begin{abstract}
Neologisms Coined by the Translator when Translating Educational and Popularizing Texts with a Scientific Content
\end{abstract}

When translating educational or popularizing texts with a scientific content into Spanish (or into Galician, etc.), the translator often has to coin and use neologisms in his/her target text, especially when such texts reflect recent research, which nowadays is documented almost exclusively in English. The proper coinage of those neologisms is a delicate act endowed with cultural significance. Those neologisms that can be coined and used by a translator belong to three categories, viz. semantic neologisms, morphological neologisms, and loanwords. The present paper reviews each of those neological strategies, and assesses, in various cases, which are the best options for the translator, resorting to the analysis of a number of published and unpublished translations (into Spanish, Galician or Portuguese) of scientific encyclopedic articles, textbooks, and popularizing articles and books written in English or German.

KEY WORDS: science education and popularization, translation equivalence, neologism, scientific-technical translation. 


\section{1. INTRODUCCIÓN}

La creación y utilización en el texto de llegada de nuevos elementos léxicos, nunca antes usados en la lengua receptora (neologismos), constituye, en general, y por motivos obvios, un lance de traducción delicado (García Yebra, 1984; Newmark, 1993), y, en particular, en el caso de la traducción de textos científicos didácticos o divulgativos, un lance de traducción relativamente frecuente y relevante, sobre todo, cuando esos textos abundan en referencias culturales o uso lúdico de la lengua (Ros, 2004), cuando reflejan la vanguardia de la investigación - hoy inicialmente documentada, casi siempre, en lengua inglesa - (Lewandowska-Tomaszczyk, 2004: 463) o cuando exploran en pormenor aspectos de la naturaleza con enfoque exótico o especializado. Si bien tales neologismos, en la mayor parte de los casos, son la respuesta del traductor a una situación traductiva de equivalencia inexistente en la lengua de llegada (Arntz, 1993: 12-15), en algunas ocasiones la incorporación al texto meta de un neologismo puede corresponder a la voluntad de corregir o mejorar una solución designativa previa que el traductor, por alguna causa, juzga insatisfactoria.

Por consiguiente, entre nosotros, la adecuada acuñación y uso de neologismos en la traducción de textos destinados a la enseñanza y divulgación de la ciencia es importante porque, sobre todo, permite que nuestras lenguas se aproximen a la eficacia comunicativa y a la corrección y vernaculidad expresivas del inglés (y, secundariamente, del alemán) en el campo científico-técnico ${ }^{1}$, resolviéndose, así, también,

I Consideremos, al respecto, el elocuente comentario de Quemada (1971: 137-138): « Il est devenu évident, pour la majorité des usagers, qu'une langue de culture moderne, nécessairement scientifique et technique, doit voir dans la un problema de «ecología cultural», ya que las esferas comunicativas de la enseñanza y de la divulgación, estrechamente vinculadas a la cultura (Domínguez, 2012: 45), son las únicas del ámbito científico-natural en las que hoy en día aún se registra un amplio cultivo de lenguas diferentes del inglés (el cual prevalece de forma absoluta en la difusión del conocimiento científico-técnico). Tal sensible circunstancia es la que, en tono apremiante, y en relación con el alemán, podemos observar en las siguientes apreciaciones de Harald Weinrich:

Ich will dieses Problem hier jedoch nicht ausloten, sondern mich damit begnügen, die englisch publizierenden Wissenschaftler der deutschsprachigen Länder daran zu erinnern, daß sie mit dem Übertritt zur publikationstechnischen Anglophonie nicht aus der Verantwortung für die deutsche Wissenschaftssprache entlassen sind. Da sie ein kulturelles Umweltproblem schaffen, bleiben sie, auch wenn sie ihren Forschungsergebnissen eine englische Sprachform geben, für die Umsetzung und Übersetzung dieses Wissenschaftsenglisch in gutes Wissenschaftsdeutsch verantwortlich und dürfen diese Aufgabe nicht angestellten Dolmetschern und Hilfskräften überlassen. Das ist insbesondere bei der Begriffsbildung zu bedenken, und kein deutschsprachiger Wissenschaftler sollte Beifall für eine englische Begriffsbildung finden, wenn er sich nicht gleichzeitig Mühe gegeben hat, dafür zu sorgen, daß diese Begriffe in mündli-

néologie lexicale autre chose qu'un mal évitable. C'est la première condition à partir de laquelle la langue peut espérer demeurer un instrument de communication national, voire international, et plus simplement rester une langue vivante. Elle doit même considérer la créativité lexicale comme l'un des gages de sa richesse immédiate, comme le signe premier de sa vitalité. Une langue qui ne connaîtrait aucune forme de néologie serait déjà une langue morte, et l'on ne saurait contester que l'histoire de toutes nos langues n'est, en somme, que l'histoire de leur néologie ». 
ches und schriftliches Wissenschaftsdeutsch gut übertragbar sind (Weinrich, 1994: 12-13) ${ }^{2}$.

En este contexto, juzgamos oportuno el presente estudio, que analiza las diferentes estrategias neológicas que un traductor de textos científicos didácticos y divulgativos puede poner en práctica, y que, a título orientativo, pondera la adecuación de diversas soluciones neológicas registradas o registrables en traducciones al castellano (y al gallego y portugués) en correspondencia con términos presentes en artículos enciclopédicos, en libros de texto y en libros y artículos de divulgación del ámbito de las ciencias naturales redactados en inglés o en alemán.

En los análisis y ponderaciones efectuados en el siguiente apartado, organizado en función de las diferentes categorías de neologismos de la traducción, nos apoyamos en ejemplos ilustrativos de tres tipos: a) neologismos acuñados por el autor del presente trabajo en gallego o portugués en un libro de texto y en un libro de divulgación del campo de la biología traducidos del alemán (Kutschera, 2013; Richarz y Kremer, 2018); b) neologismos presentes en versiones castellanas publicadas por diversos traductores de artículos de divulgación científica origi-

2 Nuestra traducción: «No deseo, sin embargo, analizar aquí en profundidad este problema, y me conformo con recordar a los científicos de los países de habla alemana que publican en inglés que, con su incorporación a la anglofonía de las publicaciones especializadas, no quedan exonerados de la responsabilidad para con la lengua científica alemana. Dado que así están creando un problema de ecología cultural, esos científicos, incluso cuando dan a los resultados de su investigación un cariz lingüístico inglés, deben asumir la responsabilidad de trasladar o transponer ese inglés científico en buen alemán científico, sin delegar esa labor en asistentes o traductores contratados. Esto debe tenerse especialmente en cuenta cuando se produce la acuñación de términos, de modo que ningún científico de habla alemana debería obtener reconocimiento por una creación terminológica en inglés si, de forma simultánea, no procura que esos conceptos tengan una buena transferencia al alemán científico oral y escrito». nalmente redactados en inglés o en alemán (v. «Fuentes de los ejemplos» en el apartado final de bibliografía); c) neologismos acuñados por el autor del presente trabajo en castellano o gallego y usados en traducciones inéditas, de uso didáctico, de artículos enciclopédicos y de artículos divulgativos, en el marco de su docencia en la Universidad de Vigo de asignaturas de traducción científico-técnica de inglés o de alemán (traducciones que siguen al rótulo «Nuestra traducción:» y aparecen encerradas entre comillas latinas simples; v. «Fuentes de los ejemplos» en el apartado final de bibliografía).

\section{ANÁLISIS EJEMPLIFICADO DE ESTRATE- GIAS NEOLÓGICAS PRACTICABLES EN LA TRADUCCIÓN DE TEXTOS CIENTÍFICOS DIDÁCTICOS Y DIVULGATIVOS}

Los neologismos que el traductor puede acuñar en su traducción, como resultado de la imitación de la correspondiente unidad léxica original, se pueden acomodar en las tres categorías siguientes (Auger y Rousseau, 1987: 46; Arntz, 1999: 80; Garrido y Riera, 2011: 123-125): neologismos de significado, instaurados cuando se utiliza un significante ya establecido con un nuevo valor semántico (Newmark, 1993: 224-226); neologismos de forma, amonedados recurriendo a los elementos morfológicos de la propia lengua receptora o de las lenguas clásicas (y que incluyen los llamados calcos semánticos [García Yebra, 1984: 341-352]), y préstamos, que surgen por la reproducción en la lengua de llegada de las unidades léxicas de la lengua de partida, sin ninguna alteración o con una adaptación a las características gráficas del código receptor (García Yebra, 1984: 333-340).

La necesidad o conveniencia de que el traductor acuñe y utilice en el texto de llegada un neologismo se presenta con cierta frecuencia en la traducción de textos científicos didácticos y di- 
478 vulgativos, y tanto más frecuentemente cuanto más reciente sea la actividad investigadora en ellos reflejada. Si bien, por lo tanto, la necesidad de amonedar y utilizar neologismos en una traducción castellana (o gallega o portuguesa, etc.) es más probable cuando se trabaja con textos de partida redactados en inglés que reflejan la investigación de vanguardia, tal operación también se podrá revelar necesaria, como veremos, al traducir textos de contenido «clásico», ya asentado, y textos compuestos en lenguas como el alemán (en los cuales los elementos léxicos que demandan la introducción de un neologismo en la lengua receptora podrán ser, a su vez, préstamos del inglés). Naturalmente, con anterioridad a la acuñación y utilización de un neologismo en su texto de llegada, el traductor deberá cerciorarse de la real indisponibilidad, de la inexistencia de un uso previo en la lengua receptora, en una forma idiomática y funcional, del pertinente elemento léxico, de modo que se evite la introducción de innecesarios y perjudiciales sinónimos (de traducción). Con ese objetivo, el traductor deberá llevar a cabo un amplio trabajo de documentación que incluya la consulta de obras lexicográficas y de documentos especializados, para lo cual hoy en día internet y sus buscadores ofrecen un potente e indispensable auxilio ${ }^{3}$.

A continuación, analizamos y ejemplificamos las diferentes categorías de neologismos acuñables y utilizables en la traducción de textos científicos didácticos o divulgativos, siguiendo la secuencia neologismos de significado (apartado 2.1.), neologismos de forma (apartado 2.2.) y

\footnotetext{
3 A veces, como veremos en algunos de los ejemplos aducidos en este trabajo, tal seguridad se ve reforzada por la explicitación que en el propio texto de partida, de reciente publicación, se efectúa de la naturaleza neológica de la correspondiente unidad léxica, con expresiones (en inglés) de tipo «it was consequently dubbed " $\mathrm{X}$ "» $\mathrm{o}$ «which we call "Y"» o «what we came to call "Z"».
}

préstamos (apartado 2.3.), conforme las hemos definido, y en cada categoría disponemos en primer lugar ejemplos de neologismos acuñados y utilizados en respuesta a una situación de equivalencia inexistente en la lengua receptora, y en segundo lugar, cuando estén disponibles, ejemplos de neologismos acuñados y utilizados para superar una solución designativa previa que se juzga insatisfactoria.

\subsection{Neologismos de significado}

En el siguiente ejemplo, el neologismo de significado (Garrido y Riera, 2011: 130-144) acuñado e incorporado por el traductor consiste en utilizar el término portugués sáurio —el cual, como su homólogo castellano saurio, en zoología denota tradicionalmente el grupo de los lagartos (= lacertilios) - con el valor semántico especial y novedoso de 'gran grupo taxonómico de reptiles (fósiles) del Mesozoico’, de acuerdo con lo que sucede con la voz Saurier en alemán (Lexikon der Biologie [Sauermost, 1999-2004]: s.v. «Saurier»; Wikipedia-de: s.v. «Saurier»), lo cual, de hecho, es declarado y explicado por el traductor en nota a pie de página:

[1] Evolutionsbiologie: 105 [epígrafe]: «4.7. Mesozoikum: Zeitalter der Saurier»

Biologia evolutiva: 162: «4.7. Mesozoico: a era dos sáurios ${ }^{11}$ [...] [Nota a pie de página:] ${ }^{11}$ De harmonia com o significado que o termo Saurier adota no original alemão, nesta tradução atribuímos à voz sáurio o valor "paleontológico restrito" de 'qualquer um dos grupos de répteis fósseis, como Dinossauros, Ictiossauros e Pterossauros', valor este que vem somar-se ao significado habitual de 'lacertílio'. De facto, em alemão, a voz Saurier (cf., p. ex., Lexikon der Biologie, s.v.), para além do significado 'lacertílio' e do "valor paleontológico restrito" enunciado, ainda pode funcionar com um valor "paleontológico amplo", no sentido de 
'qualquer tetrápode inferior fóssil (pertencente a um táxon de nome findo em -saurus)', valor este que inclui, para além de grupos de répteis extintos como os Dinossauros, Ictiossauros e Pterossauros, também anfíbios extintos, como os Microssauros, Trematossauros ou Plagiossauros. (N. do T.)»

En el siguiente ejemplo, el uso del neologismo saurio como 'organismo perteneciente a los grandes grupos de reptiles extintos del Mesozoico' se encuadra en un texto procedente de la práctica docente del autor:

[2] Naturw. Rdsch., 11/2004: 621: «Dass Flugsaurier auch anderen Räubern zum Opfer fielen, zeigte vor einigen Jahren der Skelettrest eines kleinen Flugsauriers aus der oberen Trias von Norditalien, der zu einem Knäuel zusammengepresst war. Dieser Fund wird als Speiballen interpretiert, der von einem Meeressaurier ausgewürgt wurde.»

Nuestra traducción: «Que los pterosaurios también caían presa de otros carnívoros lo mostraron hace algunos años los restos esqueléticos de un pequeño pterosaurio del Triásico Superior del norte de Italia, los cuales aparecieron comprimidos formando un ovillo, hallazgo, éste, que, de hecho, se interpreta que corresponde a una egagrópila regurgitada por un saurio marino».

Neologismo gallego de significado del campo de la ecología es el creado por el traductor en el siguiente pasaje, en el que el verbo ramalhar, derivado del sustantivo ramalho 'rama pequeña de árbol o arbusto', que ya significaba 'agitar o agitarse las ramas de los árboles', es utilizado como equivalente del término alemán äsen (y del inglés to browse y del castellano ramonear):

[3] Organismische Rekorde: 222: «Dabei regulieren spezielle Venenklappen im Hals der Tiere den Blutstau zum Gehirn, wenn sie ihren Hals zum Äsen in hohen Bäumen noch länger machen oder ihn zum Trinken zur Erde herabbeugen.»
Recordes dos seres vivos: 230-231: «Com essa finalidade, no pescoço da girafa há umhas válvulas venosas especiais que regulam a acumulaçom de sangue no encéfalo quando o animal estica o pescoço para ramalhar em árvores altas ${ }^{76}$ ou quando o abaixa até ao solo para beber. [...] [Nota a pie de página: $]^{76}$ Para vertermos a expressom original «zum Äsen in hohen Bäumen», que remete para um tipo de fitofagia em que um fitófago (ou, em rigor, um filófago) se alimenta de folhas, rebentos tenros e frutos de plantas de porte alto, geralmente lenhosas, optamos por cunhar aqui o neologismo galego-português ramalhar (e ramalhador), derivado de ramalho, preenchendo, assim, umha necessidade designativa (dos textos de zoologia e ecologia) que as vozes filófago e folívoro nom satisfám plenamente (cf. cast. ramonear - ramoneador, ingl. to browse - browser - browsing, al. zweig- und laubfressendes Tier). (N. do T.)»

El neologismo de significado que a continuación se analiza procede de la práctica docente del autor y se identifica con el equivalente castellano (y gallego y portugués) del sustantivo inglés Neandert(h)al(er) (y del alemán Neandertaler), de modo que, para superar el extendido uso en castellano, gallego y portugués de neandertal con el sentido de 'hombre de Neandertal', se propone la utilización con ese valor, más lógica y coherente, del gentilicio neandertalense (de forma coherente, por ejemplo, con denisovano [= hombre de Denisova; ingl. Denisovan, al. Denisovaner] $)^{4}$ :

[4] Sci. Am., 8/2020: 56: «We are the only humans, but not so long ago we had company. In the roughly 300,000 years of our existence, Homo sa-

4 La versión más reciente del Diccionario de la lengua española, de la RAE, registra, con el sentido de 'hombre de Neandertal', además de hombre de Neandertal, la (poco coherente) solución neandertal, y no neandertalense; a su vez, el magno diccionario brasileño Houaiss incluye el lema neandertalense, pero solo en el sentido de 'referente a la localidad alemana de Neandertal, o su natural o habitante'. 
piens has shared the planet with at least four other human species. [...] Going back 100,000 years ago, if you were to guess which human species was going to make it, one of the other humans, perhaps Neandertals, would have been a good bet.»

Nuestra traducción: «Nosotros somos ahora los únicos seres humanos, pero, no hace mucho tiempo, teníamos compañía. En los cerca de 300.000 años que llevamos existiendo, Homo sapiens ha compartido el planeta con, al menos, otras cuatro especies humanas. [...] Retrocediendo hasta hace 100.000 años, si usted tuviese que predecir qué especie humana iba a triunfar, una buena apuesta habría sido cualquiera de los otros seres humanos, quizá los neandertalenses».

\subsection{Neologismos de forma}

Cuando la imitación de la unidad léxica original que consta en el texto de partida lleva al traductor a efectuar composición o derivación con palabras de la lengua de llegada, o (re)composición o derivación con formantes de las lenguas clásicas (latín y griego), el elemento léxico novedoso que se incorpora al texto meta es un neologismo de forma (Garrido y Riera, 2011: 145-148).

Los neologismos de forma de acuñación más sencilla son aquellos que deben imitar el esquema formal y semántico de un elemento original que consiste en una palabra integrada por radicales grecolatinos o por formantes derivados de palabras vernáculas, como se muestra en los tres ejemplos siguientes (ingl. optrode > cast. optrodo; ingl. miniscope > cast. miniscopio; al. Phylogenetik > port. filogenética):

[5] Sci. Am., 11/2010: 33: «And to enable simultaneous readouts of the dynamic electrical signals elicited by optogenetic control, we have developed millisecond-scale instruments that are integrated hybrids of fiber optics and electrodes (which we call “optrodes”).»
IyC, 1/2011: 27: «Además, para medir las señales eléctricas obtenidas mediante optogenética, hemos desarrollado instrumentos, de una precisión de milisegundos, en los que se han integrado fibra óptica y electrodos ("optrodos")».

[6] Sci. Am., 7/2017: 27: «We teamed up with Peyman Golshani's and Baljit Khakh's labs, both at U.C.L.A., and together we hired a talented postdoctoral fellow, Daniel Aharoni, who went on to engineer what we came to call the U.C.L.A. miniscopes.»

IyC, 9/2017: 20-21: «Comenzamos a colaborar con los laboratorios de Peyman Golshani y Baljit Khakh, ambos en UCLA, y juntos contratamos a un investigador posdoctoral de talento, Daniel Aharoni, que ideó lo que denominamos los miniscopios de UCLA».

[7] Evolutionsbiologie: 9: «Drei Themenbereiche, die in der Erstauflage nur beiläufig dargestellt sind, wurden speziell herausgearbeitet: Beschreibungen der wichtigsten fossil erhaltenen (und rezenten) Zwischenformen, der Methoden zur molekularen Phylogenetik [...].»

Biologia evolutiva: 14-15: "Três temas que na primeira edição apenas tinha tratado de modo superficial são aqui aprofundados: a descrição das principais formas intermediárias preservadas em estado fóssil (e também recentes), a exposição dos métodos da filogenética molecular 4 [...]. [Nota a pie de página: ${ }^{4}$ Empregamos nesta tradução portuguesa o substantivo filogenética (ou Filogenética), apesar de ele não ser ainda registado em qualquer dicionário da língua geral, para traduzirmos o original alemão Phylogenetik e para significarmos a disciplina biológica, definida pela primeira vez por Ernst Haeckelem 1866, que estuda o processo da filogénese ou filogenia (al. Phylogenese, Phylogenie) e os seus resultados e, por consequência, que tem por objetivo último a reconstrução da árvore filogenética do mundo vivo. (N. do T.)»

Comentario: La opción del traductor por el neologismo filogenética obedece aquí, en parte, a la voluntad de mejorar una solución ocasionalmente 
utilizada en la bibliografía y que se revela no plenamente satisfactoria, a saber, el uso de filogenia para denotar la disciplina que estudia el proceso de la filogenia o filogénesis.

En otros casos, el neologismo de forma surge por la asociación de palabras de la lengua de llegada, separadas entre sí (términos sintagmáticos) o -en gallego y portugués, con alguna frecuencia - unidas mediante guiones. En el siguiente ejemplo, el traductor recurre a una composición sintagmática guiada por un análisis conceptual:

[8] Brockhaus-NT: s.v. "Silber": «Geringere Bedeutung für die Abtrennung von Gold haben die Scheidung mit Salpetersäure (Quartation) oder die Scheidung mit Schwefelsäure (Affination; $\rightarrow$ Gold-Silber-Scheidung). Ein spezielles Raffinationsverfahren für Rohsilber, das weitgehend frei von Gold und Platinmetallen ist, ist das »Feinbrennen «, bei dem das Rohsilber durch Schmelzen mit Salpeter u. a. und Abtreiben der Nebenbestandteile gereinigt wird, wobei man Feinsilber mit 99,9\% erhält.»

Nuestra traducción: «Menor importancia para segregar el oro de la plata tienen la separación con ácido nítrico (incuartación) o la separación con ácido sulfúrico (afinación; $\rightarrow$ separación de oro $y$ plata). Un procedimiento de refinación especial para plata bruta que en gran medida esté libre de oro y de metales del grupo del platino es la afinación con salitre, consistente en fundir la plata bruta con nitrato de potasio, entre otros compuestos, y en separar por copelación los componentes adicionales, de modo que se obtenga plata fina con una pureza del 99,9\%».

Comentario: Los diccionarios científico-técnicos bilingües de alemán-español ofrecen como equivalencia de al. Affination, en el campo metalúrgico, cast. afinación, y solo proporcionan la equivalencia (en el diccionario Ernst) «al. Silber feinbrennen > cast. afinar plata». Por consiguiente, el traductor se halla aquí ante un problema de falta de especificidad en la lengua de llegada: tanto Affination como Feinbrennen, términos que en el original aparecen en oraciones sucesivas, deben traducirse al castellano por el término genérico afinación. Ahora bien, ante la necesidad de distinguir terminológicamente los dos procesos, aquí es posible habilitar las equivalencias más específicas al. Affination > cast. afinación (con ácido sulfúrico) y al. Feinbrennen > cast. afinación con salitre, ya que Salpeter designa el salitre (= nitrato de potasio), circunstancia reflejada en la traducción propuesta.

Caso no muy feliz de tratamiento traductivo de neologismo es el que muestra el siguiente fragmento, en el que el término inglés patch clamp, designativo de una técnica de laboratorio para investigar la carga eléctrica de la membrana celular, es vertido, según nos parece, de forma semánticamente insuficiente, como técnica de pinzamiento (v. comentario anexo):

[9] BioMax-de, 15: 2-3: «Einige Jahre später entdeckten Neher und Sakmann durch Zufall, dass sich der elektrische Widerstand der Signalquelle um mehrere Zehnerpotenzen auf mehr als eine Milliarde Ohm (G $\boldsymbol{\Omega}$ ) erhöhen ließ, wenn man in der Glaspipette einen kleinen Unterdruck erzeugte und so den Membranfleck leicht ansaugte. Damit wurde das Hintergrundrauschen noch geringer, und die Forscher konnten nun auch Ionenkanäle anderer Synapsen-Typen untersuchen. Für diese mittlerweile zum Standard in den elektrophysiologischen Forschungslabors zählende Methode, die „Patch-Clamp-Technik“, bekamen die beiden Deutschen 1991 den Nobelpreis für Medizin (Abb. B).»

BioMax-es, 15: 2-3: «Años más tarde Neher y Sakmann descubrieron, por casualidad, que la resistencia eléctrica de la fuente de señal podía amplificarse en varios órdenes de magnitud, a más de mil millones de ohmios (G $\Omega$ ), si se generaba una pequeña presión negativa en la pipeta de vidrio y 
de esa manera se absorbía ligeramente el parche de membrana. Así, el ruido de fondo se redujo todavía más, y los investigadores pudieron examinar canales de iones de otros tipos de sinapsis. Por este método, llamado técnica de pinzamiento (o patch clamp), que mientras tanto es un estándar en los laboratorios de electrofisiología, los dos alemanes obtuvieron el Premio Nobel de medicina en 1991 (Fig. B)».

Comentario: Para verter patch clamp habría sido más informativa una solución neológica castellana del tipo técnica de la micrograpa, pues técnica de pinzamiento deja fuera el importante significado que en el término original aporta el substantivo atributivo patch.

Un conjunto muy caracterizado y potencialmente muy amplio de neologismos de forma pluriverbales es el de las denominaciones vernáculas (eruditas) de grupos de organismos exóticos, prehistóricos, inconspicuos o indistintos, que, en nuestras lenguas, suelen habilitarse por calco semántico a partir de los correspondientes nombres vernáculos ingleses o alemanes (Garrido, 2016: 204-271). Al efectuar tales calcos semánticos, hemos de asegurarnos —a través de una adecuada documentación del organismo correspondiente- de no caer víctimas de las celadas que algunas denominaciones vernáculas inglesas de organismos tienden al traductor, sobre todo en forma de segmentos ambiguos, como queda atestiguado en los dos casos que describimos a continuación. En la pág. 190 de la versión portuguesa (Bruce et al., 2007) de The Encyclopedia of Reptiles, Amphibians \& Invertebrates (Bruce et al., 2005), la hormiga Formica rufa, denominada en inglés (red) wood ant, aparece indebidamente rotulada como *formiga-da-madeira 'hormiga de la madera', cuando lo correcto hubiera sido formiga-florestal(-vermelha-grande) 'hormiga forestal (roja grande)' (ingl. wood > cast. madera/bosque); a su vez, la hormiga Polyergus rufescens, oriunda de Europa y Asia, y denomi- nada en inglés (European) Amazon ant debido a que, cual guerrera amazona, somete a esclavitud a los individuos de otras especies de hormigas, aparece engañosamente rotulada como *formiga-da-amazónia 'hormiga de la Amazonia' (!), cuando lo correcto hubiera sido formiga-amazona 'hormiga amazona's.

Uno de los aspectos más delicados de la acuñación de neologismos de forma en la traducción científica es el de la eventual necesidad de hacer equivaler un compuesto inglés (o alemán) integrado por una o más palabras vernáculas a un término castellano (o gallego, portugués, etc.) integrado exclusivamente por formantes grecolatinos $^{6}$. Ese compuesto inglés puede ser

5 Habiendo traducido un libro divulgativo del campo de la biología que presta atención a un gran número de especies de plantas y animales (Richarz y Kremer, 2018), el autor del presente trabajo tuvo, naturalmente, que acuñar por calco semántico (a partir del alemán y del inglés) varios neologismos en gallego del tipo denominación vernácula (erudita) de grupo de organismos: al. Eisenholzbaum (Metrosideros umbellata, pág. 138) > gall. árvore-de-ferro-do-sul (pág. 152); al. Große Rattenigel = Große Haarigel (Echinosorex gymnurus, pág. 229) > gall. ouriço-ratazana-grande = ouriço-piloso-grande (pág. 238); al. Schirmfledermaus (Sphaeronycteris toxophyllum, pág. 258) > gall. morcego-de-viseira (pág. 265); al. Greisenhaupt (Centurio senex, pág. 258) > gall. morcego-de-face-enrugada (pág. 265); al. Hummelelfe (Chaetocercus bombus, pág. 288) > gall. beija-flor-abelhom (295); al. Langnasenfledermaus (Anoura fistulata, ingl. tube-lipped nectar bat, pág. 293) > gall. morcego-de-lábio-tubular (pág. 298).

6 Un caso emblemático de este tipo concreto de acuñación de neologismos en la traducción tuvo lugar cuando las obras de Sigmund Freud fueron vertidas al inglés: «Strachey [traductor de Freud al inglés] took it for granted that psychoanalysis was a science. Scientific terminology in English traditionally relies on Latin and Greek roots to forge new words for new concepts. However, Freud himself wrote in a language that uses compounds of quite ordinary words in the natural and social sciences. Thus, where in English we use bits of Greek for hydrogen and oxygen, German uses only "plain words": Wasserstoff is "water stuff," Sauerstoff is "sour stuff," but such terms are no less technical and precise than their Greek-based counterparts in English. Consequently, where Freud says Anlehnung ("leaning on"), Strachey coins 
un término sintagmático integrado exclusivamente por voces vernáculas — como es el caso de stem cell, que, en la mejor equivalencia castellana, la propuesta por Fernando Navarro en su diccionario (Navarro, 2005: s.v.), se corresponde con blastocito o citoblasto-, o puede ser, en los últimos tiempos, un recompuesto o derivado integrado, en primer lugar, por una palabra vernácula y, en segundo lugar, por un radical o afijo (nomenclatural) grecolatinos, como, p. ej., channelrhodopsin o knottin. Esta segunda posibilidad, por desgracia hoy cada vez más frecuente, y que quiebra normas terminológicas inveteradas ${ }^{7}$, es suscitada por la exacerbada prevalencia del inglés en el campo de la investigación científica y, probablemente, por el nacionalismo intelectual de unos investigadores (anglosajones) que parece que no están familiarizados con las lenguas clásicas y, ni siquiera, con los elementos de formación de los términos científicos tradicionales. En esos casos, creemos que el traductor al castellano (o al gallego, etc.) no debe reproducir en el neologismo acuñado y usado en su texto de llegada tales elementos ingleses, y sí formular un término recompuesto que integre radicales grecolatinos (y afijos nomenclaturales) con el sentido pertinente. Tengamos en cuenta, a ese respecto, la responsabilidad cultural para con la propia lengua (científica) a la que se refería

anaclisis, and for Schaulust ("see-pleasure"), he invents scopophilia. Many now common words of English-ego, id, superego, empathy, and displacement, for example-were all first invented in Strachey's translation of Freud, to replace the equally technical but less recondite neologisms of the original: Ich, Es, Überich, Einfühlung, and Verschiebung» (Be1los, 2012: 298).

Conforme a las cuales (Garrido y Riera, 2011: 181-184), las bases que muestran sufijos nomenclaturales han de ser de raíz grecolatina o derivar de nombres propios (ej.: hemoglobina, nicotina), y si un recompuesto incorpora una palabra vernácula, ésta ha de aparecer en posición final (términos denominados «radicoléxicos», comofluvioglaciar o helipuerto).
Harald Weinrich en la cita antes transcrita, y la 483 clara función de formación cultural y lingüística que desempeñan los textos destinados a la enseñanza y divulgación de la ciencia. Es en este sentido en el que pueden verse las soluciones y reflexiones que, a propósito de la equivalencia castellana de los neologismos channelrhodopsin y knottin, constan en los dos ejemplos siguientes:

[10] Sci. Am., 11/2010: 30: «In 2002 Hegemann and Nagel described their finding that one of these sequences encoded a single-protein membrane channel responsive to blue light: when hit by blue photons, it regulated the flow of positively charged ions. The protein was consequently dubbed channelrhodopsin-1, or ChR1. The following year Nagel and Hegemann (along with their colleagues, including Ernst Bamberg in Frankfurt) explored the other sequence and named the encoded protein channelrhodopsin-2, or ChR2.»

IyC, 1/2011: 24: «En 2002, Hegemann y Nagel describieron su hallazgo: una de esas secuencias codificaba un canal de membrana formado por una proteína que respondía ante la luz azul; cuando recibía el estímulo lumínico, regulaba el flujo de iones con carga positiva. De ahí que la proteína se denominara canalorrodopsina-1, o ChR1. Durante el siguiente año, los grupos de Nagel y Hegemann exploraron la otra secuencia y nombraron canalorrodopsina-2, o ChR2a [sic, por ChR2], a la proteína que codificaba».

Comentario: En el caso de los términos ingleses bacteriorhodopsin y halorhodopsin, que se presentan en el artículo en cuestión, la equivalencia castellana se obtiene fácilmente mediante calco morfológico (> cast., respect., bacteriorrodopsina, halorrodopsina), pero el caso de la traducción de ingl. channelrhodopsin es de diferente naturaleza, porque se trata de un término compuesto de constitución «anómala», ya que su primer formante, que funciona como modificador especificador, es una palabra vernácula inglesa (ingl. channel 'tubo, conducto'), y no un formante erudito, grecolati- 
no. Aunque el alemán, p. ej., haya adoptado como equivalente la solución Channelrhodopsin o Kanalrhodopsin (Wikipedia-de: s.v. "Channelrhodopsin"), en castellano una solución similar, como *analrodopsina (o, peor, *channelrodopsina), no resultaría idiomática ni admisible. Sí, por el contrario, es idiomática la solución aquí acuñada y usada por el traductor, canalorrodopsina, que tiene la indudable ventaja, además, de vincularse claramente con canal (de membrana). Sin embargo, tal solución no está libre de algunos defectos, como el hecho de que se trate de un híbrido latín-griego, y que la vocal inflectiva (Garrido y Riera, 2011: 180) se aparte de la tradicional de los radicales latinos, que es - $i$ - (cf. canalifero, canaliforme); en ese sentido, también podría haberse recurrido - eso sí, sin una vinculación con canal (de membrana) tan clara como la de canalorrodopsina - a un radical griego (cf. -rodo- 'rojo') que signifique 'tubo, conducto', como solen (o)- (del gr. $\sigma \omega \lambda \eta \dot{v} \nu,-\nu 0 \varsigma$ ' 'tubo, conducto'), para obtenerse solenorrodopsina. En cualquier caso, creemos que en el texto de llegada tendría que haberse hecho acompañar la solución neológica castellana por el término original inglés (entre paréntesis), para facilitar su reconocimiento en la bibliografía por parte de los lectores y para justificar la sigla (convenientemente no alterada) $C h R$.

[11] Naturw. Rdsch., 11/2020: 548: «Die Peptide bestehen aus einer Sequenz von 36 Aminosäuren. Sechs Cysteine bilden drei Disulfid-Brücken, die intramolekular so verknüpft sind, dass sie mit der Peptidkette einen Knoten bilden. Peptide mit derartiger Tertiärstruktur sind bei Pflanzen und Tieren weit verbreitet und werden als ICK-Peptide (Inhibitor Cystein Knot) oder Knottine bezeichnet.»

Nuestra traducción: «Esos péptidos constan de una secuencia de 36 aminoácidos. En ellos, seis cisteínas constituyen tres puentes disulfuro, los cuales están entrelazados intramolecularmente de tal manera que, con la cadena peptídica, forman un nudo. Los péptidos que muestran esta estructura terciaria están muy extendidos entre las plantas y los animales y se designan como no- dinas (ingl. knottins) o péptidos ICK (del ingl. inhibitor cystine knot, o 'nudo de cistina inhibidor')».

Comentario: Como ya hemos visto en los casos anteriores de Patch-Clamp y de Channelrhodopsin, el alemán (de la enseñanza y divulgación científicas) es muy tolerante con los anglicismos puros, pero el castellano debe seguir, conforme a su tradición cultural, unas pautas más vernaculistas, por lo que aquí proponemos verter el neologismo inglés original knottin, constituido por la base knot 'nudo' y el sufijo nomenclatural indicativo de proteína -in por la solución castellana nodina, derivada del latín nodus 'nudo'. (En nuestra traducción se incorpora la mejora consistente en verter Cystein 'cisteína' por cistina, y no por cisteína [la cistina es un dímero oxidado de cisteína]).

\subsection{Préstamos}

Los préstamos (contemporáneos) son los neologismos de la traducción científica más conservadores de la forma original (Garrido y Riera, 2011: 123-129), pues esta se reproduce sin ninguna alteración en el texto de llegada, o con una (pequeña) adaptación a las convenciones gráficofónicas y morfológicas del sistema lingüístico receptor (ej.: ingl. spin > cast. spin o espín; ingl. (genic) pool > cast. pool (génico)). Por su hechura, los préstamos que proceden de palabras significativas en la lengua original resultan, en general y en principio, semánticamente opacos a los receptores de la comunidad sociocultural de llegada, por lo que el traductor científico, excepto en casos bien caracterizados, debería siempre priorizar los neologismos de significado o de forma (García Yebra, 1984: 335-336 y 341; ej.: ingl. genic pool > cast. acervo génico).

Por eso, y por quebrar la coherencia terminológica de nuestras lenguas, no nos parece la mejor solución el neologismo castellano que el traductor acuña y utiliza en el siguiente caso (teterina), en correspondencia con el término inglés tetherin: 
[12] Sci. Am., 11/2008: 59: «Just this year Paul D. Bieniasz of the Aaron Diamond AIDS Research Center in New York City and John C. Guatelli of U.C.S.D. and their teams independently identified a second cellular restriction, named tetherin, that prevents the release of new copies of the virus from infected cells. The virus has evolved a defense against tetherin, too-in this case, the viral Vpu protein. Drugs that stymie Vpu could prevent HIV from spreading to new cells. [...] Vpu (viral protein U): HIV-infected cells tether newly made virus to the surface, but HIV's Vpu protein sets it free. A Vpu inhibitor should keep the virus from spreading to other cells.»

IyC, 2/2009: 57: «En 2008, Paul D. Bieniasz, del Centro Aaron Diamond de Nueva York, y John C. Guatelli, de la Universidad de California en San Diego, junto con sus equipos de investigación identificaron de forma independiente la teterina, un segundo factor de restricción celular que impide la liberación de nuevas copias del virus por parte de células infectadas. El virus ha desarrollado una defensa contra la teterina: la proteína vírica Vpu. Los fármacos que bloquean a Vpu podrían evitar que el VIH se propague hacia nuevas células. [...] Vpu (proteína vírica $\mathrm{U}$ ): En las células infectadas por el VIH, los virus recién formados quedan amarrados a la superficie, pero los libera la proteína vírica Vpu. Un inhibidor de Vpu evitaría que los virus se propagaran a otras células».

Comentario: En inglés, tetherin, también designada bone marrow stromal antigen 2 y CD317 (= cluster of differentiation 317), es una proteína cuya denominación, evocadora de la función de la molécula, está constituida por la palabra vernácula tether 'cuerda para atar un animal' (o to tether 'sujetar un animal con esa cuerda') y por el sufijo nomenclatural -ina, que sirve para formar nombres de proteínas. Aunque la denominación alemana correspondiente que registra Wikipedia-de sea, una vez más, un préstamo del inglés (casi) puro (al. Tetherin), en castellano conviene naturalizar y regularizar la correspondiente denomi- nación (tradicionalmente, el primer formante de las denominaciones castellanas de las proteínas que terminan en -ina es un radical grecolatino), para lo cual se puede calcar semánticamente el formante original tether mediante un elemento de composición erudito, como el radical latino cord-, de chorda 'cuerda (de tripa)', que daría el neologismo cordina, o, tal vez mejor, el radical griego seir-, de $\sigma \varepsilon ı p \alpha ́, ~-\varsigma$ 'cuerda o cadena (con lazo)', que daría el neologismo seirina. Así, en nuestra versión, el segmento textual clave rezaría «[...] identificaron de forma independiente la seirina (ingl. tetherin), un segundo factor de restricción celular [...].»

En contraste, situación en que el préstamo resulta la solución adecuada para verter un neologismo es la ilustrada en el ejemplo siguiente, en que el neologismo en cuestión fue creado en inglés recurriendo a un elemento de una lengua indígena australiana:

[13] Naturw. Rdsch., 11/2020: 548: «Wissenschaftler der Queensland Universität in Brisbane ist es nun gelungen, aus Extrakten der Brennhaare von D[endrocnide]. excelsa und D[endrocnide]. moroides Peptide zu isolieren, die bei Versuchstieren heftige Schmerzreaktionen auslösten [3]. Sie wurden Gympietide genannt, ein Name, der der Eingeborenen-Sprache für den Brennnesselbaum, "gympie-gympie” entlehnt wurde.»

Nuestra traducción: «Un grupo de científicos de la Universidad de Queensland en Brisbane (Australia) ha conseguido aislar, a partir de extractos de los pelos urticantes de $D$ [endrocnide]. excelsa y de $D$ [endrocnide]. moroides, péptidos que desencadenaron reacciones dolorosas violentas en los animales de laboratorio [3]. Esos péptidos han sido designados como gimpiétidos, término que procede de la palabra gympie-gympie, que en la lengua de los aborígenes locales designa el árbol ortiga».

Entre los elementos neológicos ingleses de los textos científicos didácticos y divulgativos 
que, en general, no admiten otro tipo de trasvase que el préstamo puro, se encuentran las siglas, cada vez más frecuentes, que típicamente designan fenómenos, moléculas, aparatos, etc. y que tienen un «valor añadido» (Ros, 2004: 21), en el sentido de que (deliberadamente) coinciden con palabras inglesas, como, por ejemplo, SHRIMP (por sensitive high-resolution ion microprobe), que remite al ingl. shrimp 'camarón' (Sci.Am., 10/2005: 45). Esta circunstancia incrementa la pregnancia o poder evocador de las siglas inglesas y hace prácticamente imposible que puedan ser adaptadas o traducidas a otras lenguas.

En este contexto, un caso harto interesante es el siguiente (ej. 14 y 15), en el que, a pesar de aparecer en el texto de partida una de esas siglas inglesas «verbalizadas» (aquí, NETs), el traductor, dadas las especiales circunstancias concurrentes, y haciendo uso de una discrecionalidad bien fundamentada, opta por secundarizar el correspondiente préstamo síglico:

[14] BioMax, 30: 2, 4: «Die Waffen der angeborenen Immunabwehr schienen also bekannt dachte man zumindest bis 2003. Aber das, was Arturo Zychlinsky und Volker Brinkmann jetzt zum ersten Mal unter dem Lichtmikroskop sahen, war etwas anderes: Die Neutrophilen hatten sich ganz offenbar in den Selbstmord gestürzt. Die Zellen waren aufgeplatzt, und zwar einschließlich der Membran des Zellkerns. Dabei war die DNA dekondensiert und hatte - wie bei einem aufgelösten Knäuel Wolle - Fäden aus Chromatin über die Mikroben ausgeworfen, die nun wie Fische im Netz zappelten (Abb. A). „Neutrophil extracellular traps" oder kurz NETs nannten die beiden Max-Planck-Forscher ihre Entdeckung. // Trotzdem, NETs aus DNA und Histonen, die zur Immunabwehr ausgeworfen werden, sind - wie man inzwischen weiß - im Organismenreich weit verbreitet: Beim Menschen werden sie nicht nur von Neutrophilen produziert, sondern auch von
Mastzellen, einer weiteren Art von Immunzellen. Analoge Strukturen wurden bei anderen Säugetieren, Vögeln und Fischen beschrieben. Auch Insekten machen NETs, wobei sie aber RNA statt DNA einsetzen, und selbst bei Pflanzen konnten NETs gefunden werden.»

Nuestra traducción: «Por consiguiente, las armas de la defensa inmunitaria innata parecían conocidas, o, por lo menos, eso era lo que se pensaba en 2003. Sin embargo, lo que Arturo Zychlinsky y Volker Brinkmann veían ahora por primera vez al microscopio óptico era algo diferente: los neutrófilos se habían entregado claramente al suicidio, ya que habían explosionado en su totalidad, desintegrándose incluso la membrana nuclear; el ADN estaba descondensado y había desparramado, como un ovillo de lana deshecho, filamentos de cromatina sobre los microbios, que ahora se agitaban como peces en una red (ilustr. A). Los dos investigadores del Instituto Max Planck designaron lo que acababan de descubrir como neutrophil extracellular traps (en inglés, literalmente, 'trampas extracelulares de los neutrófilos'), abreviadamente NETS [término cuyo mejor equivalente castellano es trampas reticulares]. // No obstante, las trampas reticulares, compuestas por ADN e histonas, y que son lanzadas como parte de la defesa inmunitaria, se presentan con frecuencia, como ahora se ha descubierto, entre los seres vivos: así, en el ser humano no solo son producidas por los neutrófilos, sino también por los mastocitos, que constituyen otro tipo de célula inmunitaria, y estructuras análogas se han descrito en otros mamíferos, en las aves y en los peces. Además, también los insectos producem trampas reticulares, aunque estas presentan ARN en vez de ADN, e incluso en las plantas también se han podido encontrar».

comentario: El término trampa extracelular de los neutrófilos, literalmente calcado del original inglés neutrophil extracellular trap (término cuya hechura probablemente fue determinada para dar la sigla NET) presenta varias desventajas: es largo en exceso, su componente extracelular es poco expresivo y 
dispensable y su componente de los neutrófilos está errado, ya que, como se explica en la pág. $4 \mathrm{del}$ propio artículo (v. supra), este recurso defensivo del sistema inmunitario también es aprovechado por los mastocitos, y análogos suyos se presentan en organismos vegetales. Por esas razones, acuñamos y utilizamos en nuestra traducción el neologismo trampa reticular, que no adolece de las desventajas señaladas y que, además, tiene la ventaja de armonizar con (pág. 3) reticulosis, neologismo que, como se ve en el siguiente ejemplo, hacemos corresponder con al. Netose (= ingl. netosis).

[15] BioMax, 30: 2-3: «Sind die NETs erst einmal ausgeworfen, breiten sie sich über eine 10- bis 15fach größeren Raum aus als das ursprüngliche Zellvolumen. Die Mikroben werden dabei durch Unterschiede in der elektrischen Ladung auf der Oberfläche in den NETs fest gehalten. Und obwohl in der letzen Phase der Netose - so haben die Forscher diesen Vorgang getauft - durch Auflösung der Membranen die zellulären Kompartimente arg durcheinander gemischt werden, sind weniger als 30 verschiedene Proteine in den NETs vertreten.»

Nuestra traducción: «Una vez que se han lanzado las trampas reticulares, estas se extienden sobre un espacio que es de 10 a 15 veces superior al volumen celular original y, así, los microbios quedan aprisionados en ellas debido a diferencias de carga eléctrica existentes en su superficie. Aunque en la última fase de la reticulosis (= ingl. netosis, como los investigadores han denominado a este proceso), y a causa de la disolución de las membranas, los compartimentos celulares quedan mezclados totalmente, se ha comprobado que en las trampas reticulares están representadas menos de 30 proteínas diferentes» ${ }^{8}$.

8 Afligidos como ahora estamos por la pandemia de covid-19, no podíamos dejar de mencionar aquí el surgimiento de la sigla NETs también en textos muy recientes que tratan sobre la patogenia del SARS-COV-2:

[16] Sci. Am., 1/2021: 36: «Recent papers suggest why neutrophils may be a culprit in COVID-19 pathology. These cells extrude neutrophil extracellular traps (NETs), which

\section{CONCLUSIONES}

En el marco de la traducción al castellano (o al gallego, etc.) de textos destinados a la enseñanza y divulgación de la ciencia, es frecuente que el traductor deba acuñar y utilizar en su texto de llegada neologismos, sobre todo cuando tales textos abundan en referentes culturales, cuando exploran la naturaleza con enfoque exótico y especializado o cuando reflejan la vanguardia de la investigación, hoy en día documentada casi exclusivamente en inglés. Los neologismos son acuñados por el traductor, en general, como respuesta a una situación de equivalencia inexistente en la lengua receptora, pero, ocasionalmente, también para corregir o mejorar una designación previa que se juzga insatisfactoria.

La adecuada acuñación de esos neologismos es una operación delicada y que reviste importancia cultural, dado que es en los textos destinados a la socialización del conocimiento científico, y no en los de investigación (por lo general, redactados en inglés), en los que, precisamente, se pueden establecer y difundir en nuestras lenguas las correspondientes denominaciones ${ }^{9}$. Los neolo-

consist of webs of DNA, antimicrobial proteins and enzymes that sequester and kill pathogens. Unfortunately, NETs can also damage tissue.»

Nuestra traducción: «Una serie de trabajos de reciente publicación señalan por qué los neutrófilos pueden encontrarse entre los culpables de los efectos asociados a la covid-19. Estos leucocitos expulsan trampas reticulares (en inglés, NETs), que consisten en una red formada por filamentos de ADN, proteínas antimicrobianas y enzimas que inmovilizan y matan los patógenos. Por desgracia, las trampas reticulares también pueden dañar los tejidos».

9 Por ejemplo, tras publicarse la traducción al gallego del libro divulgativo de Richarz y Kremer (2018), efectuada por el autor del presente trabajo, el mayor diccionario de gallego, el e-Estraviz (www.estraviz.org), pasó a incorporar (diciembre de 2018) los neologismos (antes citados) árvore-de-ferro, ouriço-piloso, ouriço-ratazana, ramalhar y ramalhador, así como los dos siguientes, también acuñados y utilizados en esa tra- 
488 gismos acuñables y utilizables por un traductor de textos científicos didácticos y divulgativos pueden ser de tres categorías, a saber, neologismos de significado, neologismos de forma y préstamos. El presente trabajo pasa revista a cada una de esas estrategias neológicas y, recurriendo al análisis de diversas traducciones (al castellano, gallego y portugués), tanto publicadas como inéditas, de artículos enciclopédicos, libros de texto y artículos y libros divulgativos del ámbito científico redactados en inglés o alemán, pondera en cada caso cuáles son las mejores opciones para el traductor.

En concreto, el presente estudio indica que, en la categoría de los neologismos de significado, en algunos casos es conveniente que el traductor incluya una nota para explicar el correspondiente valor semántico novedoso incorporado. En la categoría de los neologismos de forma, los casos más complicados, por implicar un «salto traductivo», son aquellos en los que el término de llegada debe ser constituido por formantes eruditos (clásicos), mientras que el término original (inglés o alemán) consta de componentes vernáculos; en esta categoría, debe tenerse especial cuidado con dos clases de neologismos que cada vez son más frecuentes en inglés y que violentan las normas terminológicas tradicionales: los términos recompuestos en los que el primer elemento es vernáculo y no hay vocal inflectiva (ej., channelrhodopsin) y los términos derivados mediante afijos nomenclaturales a partir de una base vernácula (ej., knottin, tetherin). Por otro lado, si bien los neologismos de alguna clase concreta, como las siglas «con valor añadido», es necesario trasladarlos como préstamos, estos, en general, deben ser evitados por el traductor, dada su frecuente opacidad

ducción y que no fueron antes mencionados: metrossidero 'árbol del género Metrosideros' y toquiano 'natural de Tokio'. para el público receptor y, en el caso de términos de los tipos representados por channelrhodopsin y por tetherin, dada la ruptura de la coherencia terminológica (grecolatina) que acarrean.

En cualquier caso, al acuñar un neologismo en el marco de la traducción de textos científicos didácticos y divulgativos, el traductor siempre deberá actuar con pleno conocimiento de las estrategias neológicas disponibles y con buen margen de libertad para, en caso conveniente, y en beneficio de la idiomaticidad y de la funcionalidad en el sistema receptor, renunciar a una imitación formal estrecha y alejarse del significante original.

\section{BIBLIOGRAFÍA}

\subsection{Referencias citadas}

ARNTZ, Reiner (1993): «Terminological Equivalence and Translation», en H. B. Sonneveld y K. L. Loening (coord.), Terminology Applications in Interdisciplinary Communication, Ámsterdam: John Benjamins, 5-19.

ARnTZ, Reiner (1999): «Terminologie der Terminologie», en Mary Snell-Hornby, Hans G. Hönig, Paul Kußmaul y Peter A. Schmitt (coords.), Handbuch Translation, 2. ${ }^{\mathrm{a}}$ ed., Tubinga: Stauffenburg, 77-82.

Auger, Pierre y Louis Rousseau (1987): Metodologia de la recerca terminològica, trad. y adapt. Maria Teresa Cabré, Barcelona: Departament de Cultura de la Generalitat de Catalunya.

BeLlos, David (2012): Is That a Fish in Your Ear? Translation and the Meaning of Everything, Nueva York: Farrar, Straus and Giroux.

DomínguEZ, Martí (2012): «Ciencia vs. lengua. El catalán como lengua de ciencia», en F. Díaz-Fierros Viqueira y X. Mariño Alfonso (coords.), Escribir de ciencia en galego, Santiago de Compostela: Consello da Cultura Galega, 41-48.

García YeBra, Valentín (1984): en Teoría y práctica de la traducción. Tomo I, 2. a ed., Madrid: Gredos.

GARRIDO, Carlos (2016): A traduçom do ensino e divulgaçom da ciência, Vigo: Servizo de Publicacións da Universidade de Vigo. 
GARRIDO, Carlos y Carles Riera (2011): Manual de galego científico. Orientaçons lingüísticas, $2 .^{\mathrm{a}} \mathrm{ed}$., Santiago de Compostela: Através Editora.

KuTSCHERA, Ulrich (2013): Biologia evolutiva, trad. Carlos Garrido Rodrigues, Lisboa: Fundação Calouste Gulbenkian.

LEWANDOWSKA-TOMASZCZYK, Barbara (2004): «Lexical problems of translation», en Harald Kittel, Armin Paul Frank, Norbert Greiner, Theo Hermans, Werner Koller, José Lambert y Fritz Paul (coords.), Übersetzung/Translation/Traduction, Handbücher zur Sprach- und Kommunikationswissenschaft, n. ${ }^{\circ}$ 26.1, Berlín/Nueva York: Walter de Gruyter, 455-465.

NAVARro, Fernando A. (2005): Diccionario crítico de dudas inglés-español de medicina, 2. ${ }^{\mathrm{a}}$ ed., Madrid: McGraw-Hill/Interamericana.

Newmark, Peter (1993): Manual de traducción, trad. Francisco Xabier Fernández Polo, Santiago de Compostela: Universidade de Santiago de Compostela, 223-238.

QuemadA, Bernard (1971): «À propos de la néologie. Essai de délimitation des objectifs et des moyens d'action», La banque des mots, 5, 137-150.

RicharZ, Klaus y Bruno P. Kremer (2018): Recordes dos seres vivos. Anaos e gigantes: das bactérias aos vertebrados, trad. Carlos Garrido Rodrigues, Santiago de Compostela: Edicións Laiovento.

Ros, Joandomènec (2004): «Reflexons de um tradutor científico sobre a grandeza e a servidom do ofício», en Carlos Garrido (coord.), Ferramentas para a traduçom, Santiago de Compostela: Associaçom Galega da Língua, 11-26.

SAUERMOST, Rolf (dir.) (1999-2004): Lexikon der Biologie, Heidelberg: Spektrum Akademischer Verlag/ Elsevier, s.v. «Saurier».

WEINRICH, Harald (1994): «Sprache und Wissenschaft», en Heinz Leonhard Kretzenbacher y Harald Weinrich (coords.), Linguistik der Wissenschaftssprache, Akademie der Wissenschaften zu Berlin, Forschungsbericht 10, Berlín/Nueva York: De Gruyter, 3-13.

Wikipedia. Die freie Enzyklopädie <http://de.wikipedia. org>, s.v. «Channelrhodopsin», «Saurier» [consulta: $15-$ I-2021].

\subsection{Fuentes de los ejemplos}

AA.VV. (2003): Der Brockhaus Naturwissenschaft und Technik, Mannheim/Heidelberg: F. A. Brockhaus/ Spektrum Akademischer Verlag, s.v. «Silber».

BECK, Christina (2004a): «Spannung auf allen Kanälen - Wie Ionen durch die Zellmembran schlüpfen», BioMax, 15.

BECK, Christina (2004b): «Tensión en todos los canales. Cómo los iones se deslizan a través de la membrana celular», trad. Roberto Neuwald, BioMax [ed. en español], 15.

BECK, Christina (2013): «Ins Netz gegangen - unbekannte Waffe unseres Immunsystems entdeckt», BioMax, 30.

BRUCE, Jenni, Karen McGhee y Richard Vogt (2005): The Encyclopedia of Reptiles, Amphibians \& Invertebrates, Oakland: University of California Press.

Bruce, Jenni, Karen McGHeE y Richard Vogt (2007): Enciclopédia dos répteis, anfíbios e invertebrados: um guia visual completo, trad. Sofia Gomes, rev. Filipe Machado, Mem Martins: Círculo de Leitores.

DeISSEROTH, Karl (2010): «Controlling the Brain with Light», Scientific American, 11/2010, 28-35.

DeIsSERoth, Karl (2011): «Control del cerebro por medio de la luz», trad. Juan Manuel González Mañas, Investigación y Ciencia, 1/2011, 22-29.

HARE, Brian y Vanessa Woods (2020): «Survival of the Friendliest», Scientific American, 8/2020, 54-59.

IWASAKI, Akiko y Patrick Wong (2021): «The Immune Havoc of COVID-19», Scientific American, 1/2021, 30-37.

KutsChERA, Ulrich (2008): Evolutionsbiologie, 3. ${ }^{\mathrm{a}}$ ed., Stuttgart: Eugen Ulmer Verlag.

KUTSCHERA, Ulrich (2013): Biologia evolutiva, trad. Carlos Garrido Rodrigues, Lisboa: Fundação Calouste Gulbenkian.

Mebs, Dietrich (2020): «Der giftige Brennnesselbaum», Naturwissenschaftlich Rundschau, 11/2020, 548-549.

RichARZ, Klaus y Bruno P. Kremer (2017): Organismische Rekorde. Zwerge und Riesen - von den Bakterien bis zu den Wirbeltieren, Berlín: Springer Verlag.

RicharZ, Klaus y Bruno P. Kremer (2018): Recordes dos seres vivos. Anaos e gigantes: das bactérias aos verte- 
490 brados, trad. Carlos Garrido Rodrigues, Santiago de Compostela: Edicións Laiovento.

Silva, Alcino J. (2017): «Memory's Intricate Web», Scientific American, 7/2017, 22-29.

SilvA, Alcino J. (2017): «La intrincada red de la memoria», trad. Raquel Reboredo e Ignacio Navascués, Investigación y Ciencia, 9/2017, 16-23.

Stevenson, Mario (2008): «Can HIV Be Cured?», Scientific American, 11/2008, 54-59.

STEVEnson, Mario (2009): «Farmacoterapias contra el VIH», trad. Juan Manuel González Mañas, Investigación y Ciencia, 2/2009, 51-57.

Wellnhofer, Peter (2004): «Flugsaurier als Dinosauriermahlzeit», Naturwissenschaftliche Rundschau, 11/2004, 621. 